\title{
The big CGRP flood - sources, sinks and signalling sites in the trigeminovascular system
}

\author{
Karl Messlinger(1)
}

\begin{abstract}
Background: Calcitonin gene-related peptide (CGRP) has long been a focus of migraine research, since it turned out that inhibition of CGRP or CGRP receptors by antagonists or monoclonal IgG antibodies was therapeutic in frequent and chronic migraine. This contribution deals with the questions, from which sites CGRP is released, where it is drained and where it acts to cause its headache proliferating effects in the trigeminovascular system.

Results: The available literature suggests that the bulk of CGRP is released from trigeminal afferents both in meningeal tissues and at the first synapse in the spinal trigeminal nucleus. CGRP may be drained off into three different compartments, the venous blood plasma, the cerebrospinal fluid and possibly the glymphatic system. CGRP receptors in peripheral tissues are located on arterial vessel walls, mononuclear immune cells and possibly Schwann cells; within the trigeminal ganglion they are located on neurons and glial cells; in the spinal trigeminal nucleus they can be found on central terminals of trigeminal afferents. All these structures are potential signalling sites for CGRP, where CGRP mediates arterial vasodilatation but not direct activation of trigeminal afferents. In the spinal trigeminal nucleus a facilitating effect on synaptic transmission seems likely. In the trigeminal ganglion CGRP is thought to initiate long-term changes including cross-signalling between neurons and glial cells based on gene expression. In this way, CGRP may upregulate the production of receptor proteins and pro-nociceptive molecules.
\end{abstract}

Conclusions: CGRP and other big molecules cannot easily pass the blood-brain barrier. These molecules may act in the trigeminal ganglion to influence the production of pronociceptive substances and receptors, which are transported along the central terminals into the spinal trigeminal nucleus. In this way peripherally acting therapeutics can have a central antinociceptive effect.

\section{Preface}

The title of the EHF Lecture was inspired by the famous allegorical woodcut "The Great Wave of Kanagawa" by Katsushika Hokusai (1760-1849) with the idea of two recent scientific and clinical phenomena that made calcitonin gene-related peptide (CGRP) popular in migraine research: first, the wave of CGRP that may flush our head during a migraine attack, and second, the hype about new options in migraine therapy by blocking the CGRP system. What is so special about this neuropeptide, a member of a family of peptides, which in a

Correspondence: karl.messlinger@fau.de

This review is based on the EHF Lecture 2017 presented at the EHF Congress 2017 at Rome.

Institute of Physiology and Pathophysiology, Friedrich-Alexander-Universität Erlangen-Nürnberg, Universitätsstr. 17, 91054 Erlangen, Germany similar form is already functional in the most primitive chordate animals like Amphioxus [47], and which is now regarded as a key mediator in migraine headache; the plasma level of which has been used as a biomarker for migraine; and, when its actions are blocked, migraine attacks may be prevented or stopped?

\section{Discovery of CGRP and first functional findings}

CGRP was firstly described as a splice product of the calcitonin gene in two well-recognized papers by Amara et al. [2] and Rosenfeld et al. [41]. They found calcitonin mRNA predominating in the rat thyroid, while mRNA for another peptide, which they named calcitonin generelated peptide, predominated in the hypothalamus and other neural tissues. Shortly after these findings, Mason et al. [35] reported about the release of immunoreactive 
CGRP from cultured rat trigeminal ganglion cells, and Wiesenfeld-Hallin et al. [53] subsequently showed that dorsal root ganglion neurons and their putative terminals in the spinal dorsal horn were marked by CGRP immunofluorescence, partly co-stained by substance $\mathrm{P}$ immunofluorescence. A similar finding was also described for the trigeminal ganglion by Lee et al. [30]. Around the same time Edvinsson et al. [12] were the first to describe the potent relaxing effect of CGRP on feline cerebral arteries, an effect concomitant with an accumulation of cyclic adenosine monophosphate (cAMP). Consistent with this, Uddman et al. [52] demonstrated by immunohistochemistry and radioimmunoassay that CGRP containing nerve fibers surround these blood vessels. Shortly after these reports the same group showed clearly the important role of CGRP in cerebrovascular regulation, specifically as a function of trigeminal nerve fibers antagonizing local and sympathetic vasoconstrictory effects [36].

The following considerations about the release, draining and signalling of CGRP are restricted to the trigeminovascular system. This system constitutes a functional unit of intracranial blood vessels and their trigeminal innervation and is the most likely source of nociceptive events that lead to headaches [40].

\section{Sources for CGRP in the trigeminovascular system}

In the trigeminovascular system, the immunohistochemical identification of CGRP has been used to identify the sources, from which this neuropeptide is potentially released (Fig. 1). The cranial dura mater is innervated by CGRP immunoreactive nerve fibres running along the meningeal arteries and terminating at their branches but also between blood vessels in the connective tissue [38]. Stimulation of meningeal afferents by substances like capsaicin in an ex vivo preparation of the hemisected rodent head caused release of immunoreactive CGRP quantified by an ELISA [10]. This stimulation may render the smooth shape of CGRP-ir nerve fibres perl-like supposing a re-distribution of CGRP prior to its release [23]. Likewise, pial and intracerebral arteries are innervated by CGRP immunoreactive trigeminal afferent fibres [11]. An additional site of potential CGRP release in the trigeminal system is the trigeminal ganglion, which, in rodents and humans, contains CGRP immunoreactive neurons of mainly small diameter that make up nearly half of the neuronal population [17, 31]. Looking to the central nervous system, a dense plexus of CGRP immunoreactive fibres in the superficial layers of the spinal trigeminal nucleus represents the central terminals of these neurons [15]. From both isolated rodent trigeminal ganglia and medullary slices containing these terminals, considerable amounts of immunoreactive CGRP could be released by noxious agents like capsaicin [29]. The anti-migraine drug naratriptan did not significantly inhibit capsaicin-induced CGRP release from peripheral terminals but inhibited the release from brainstem slices suggesting a potential central effect of triptans, if they penetrate the blood brain barrier.

\section{Sinks for CGRP in the trigeminovascular system}

During migraine attacks increased concentrations of CGRP have been found in the plasma of the internal jugular vein [13] but the intracranial sinks of the drained CGRP are not clearly known. It is assumed that CGRP is released from intracranial sources into the venous blood, most likely from activated primary afferents. An increase in jugular plasma CGRP was measured following topical application of depolarizing concentrations of potassium chloride $(\mathrm{KCl})$ onto the exposed rat parietal dura mater [8] suggesting that CGRP released from dural afferent fibres is taken up into the meningeal venous system and transported via the sagittal sinus to the jugular vein (Fig. 1a). Interestingly, after infusion of a CGRPbinding L-RNA oligonucleotide, the Spiegelmer NOXC89, CGRP has accumulated in the plasma, which may indicate that in an unbound state CGRP is rapidly eliminated from the blood plasma. Action potentials elicited through excitation of meningeal afferents certainly reach the somata within the trigeminal ganglion and may also cause CGRP release there, though we have only evidence from in vitro studies for this assumption [9]. However, since blood vessels supplying the ganglion do not have a blood-brain barrier (BBB), like those supplying the cranial dura [18], the released CGRP is also drained via the venous plasma and can contribute to the plasma CGRP values measured in jugular blood (Fig. 1b).

In contrast, pial blood vessels on the surface of the cerebral cortex and medulla oblongata are equipped with a BBB. It is likely that CGRP does not penetrate the BBB with the consequence that, when it is released from nerve fibres innervating these vessels, it cannot reach the vessel lumen but must diffuse into the surrounding perivascular space bordered by a layer of leptomeninx and finally into the cerebrospinal fluid (CSF) within the subarachnoid space (Fig. 1a, b). Indeed, five times higher concentrations of CGRP can be measured in the rat CSF compared to the plasma [8]. The CGRP concentration in the CSF could further be increased when noxious inflammatory mediators were injected into the ventricle system [24]. However, the administration of inflammatory mediators also increased levels of CGRP in jugular plasma, probably indicating that CGRP is rapidly absorbed together with the CSF through the arachnoid granulations extending into the superior sagittal sinus.

It is very likely, however, that the CSF is also the sink for CGRP from a different source, namely CGRP released from the activated central terminals of primary 

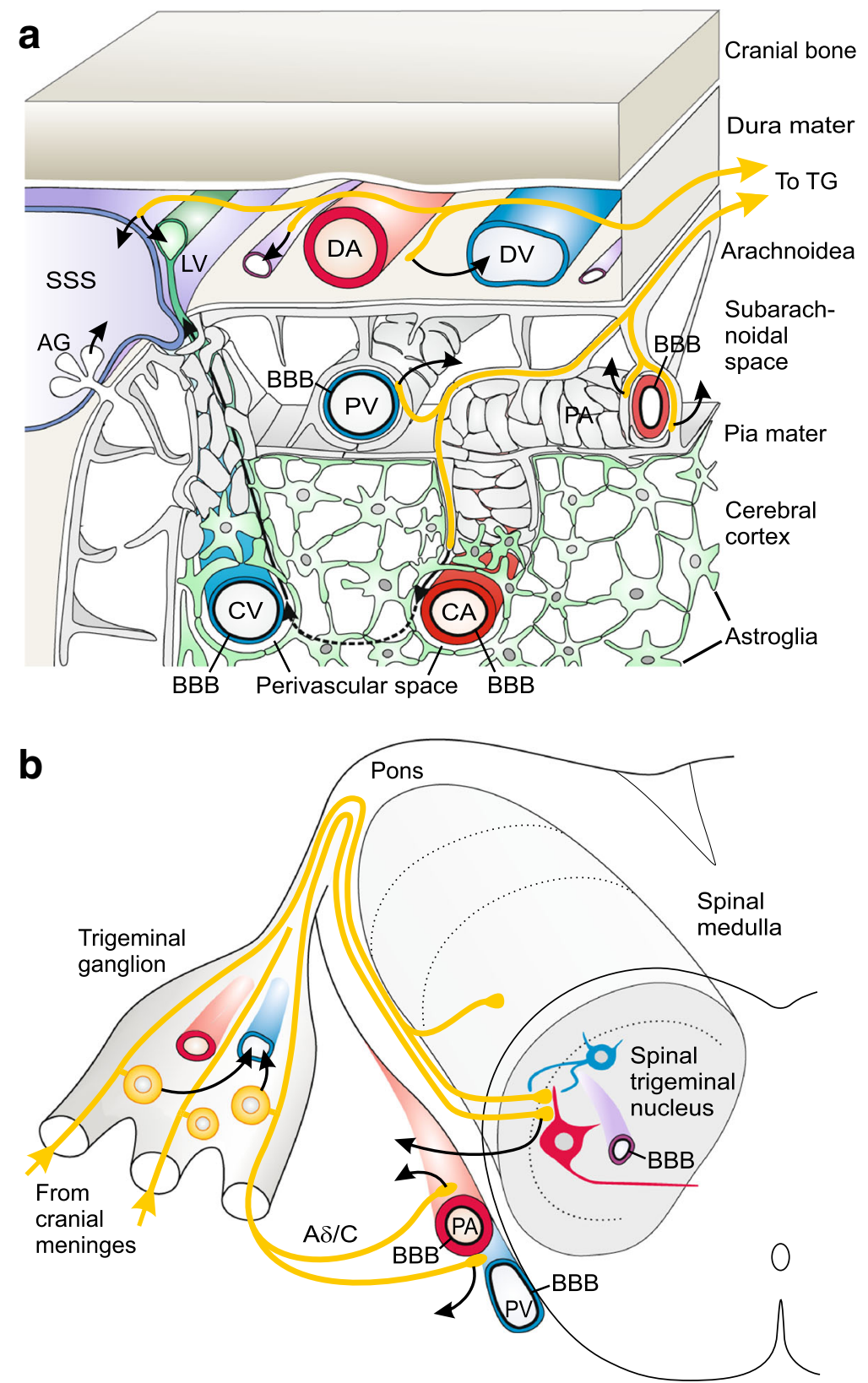

Fig. 1 Scheme of sources and sinks for CGRP (curved arrows) in the trigeminovascular system, ameninges, $\mathbf{b}$ trigeminal ganglion and spinal trigeminal nucleus. CGRP released from trigeminal afferent fibers innervating dural arteries (DA) is most likely taken up from capillaries, venous vessels (DV) and possibly the superior sagittal sinus (SSS), and is transported with the blood stream into the internal jugular vein. The same may occur in the trigeminal ganglion, which is located outside the blood-brain barrier (BBB). However, a BBB is functional in pial arteries (PA) and veins (PV). Thus, CGRP released from perivascular afferent fibres cannot enter the vessels but diffuses into the surrounding cerebrospinal rooms, the subarachnoidal space or the cerebello-medullary cisterna (cisterna magna), respectively, where it can be found in the cerebrospinal fluid (CSF). Probably part of it is secreted through the arachnoid granulations (AG) into the SSS and appears secondarily also in the jugular blood. CGRP released from the central terminals of trigeminal afferents within the spinal trigeminal may move out of the medulla into the cisterna magna. Innervated cortical arterioles (CA) arising from penetrating pial arteries may also be innervated by trigeminal afferents. Here, CGRP may be released into the perivascular space between the vessel wall and the surrounding astroglial end-feet. Then it may be transported with the glymphatic flow through the brain tissue and collected in the venous perivascular spaces. CGRP may move together with the extracellular fluid within these spaces along the venous vessels through the subarachnoidal space to the dura mater, where it may be finally collected in lymphatic vessels (LV) accompanying the SSS 
afferents in the spinal trigeminal nucleus (Fig. 1b). The medullary blood vessels are also equipped with a BBB that prevents inward diffusion of peptides. These peptides may diffuse to the surface of the medulla and into the surrounding CSF, as has been suggested by earlier radiographic measurements of neuropeptide release using a microprobe technique [43]. In line with this assumption, CGRP levels in the CSF were also increased by activating dural afferents with depolarizing $\mathrm{KCl}$ [8]. This increase was abolished by preceding anaesthesia of the trigeminal ganglion, suggesting that the increased CGRP appearing in the CSF was released by the central terminals of activated meningeal afferents.

In this context the potential importance of the recently described glymphatic system should be discussed as an additional sink for CGRP. This lymphatic-like system consists of a small extracellular space between the wall of intracerebral blood vessels and the astroglial end-feet surrounding the vessels. This space may be in continuation with the Virchow-Robin space of the penetrating arteries, although such a connection has not been confirmed by anatomical data [55]. However, tracer experiments in rodents suggest that CSF is driven from the subarachnoid space along the pial arteries into the perivascular space of intracerebral arterial vessels [26] from which fluid can move into and out of the astrocytes by aquaporines, ion channels and transporters [1]. Via the interconnected astrocytes a convective flow is assumed to move through the brain from the perivascular space of cerebral arteries to the perivascular space of venous vessels, and in this way substances accumulating in the brain can be washed into the venous glymphatic system [51]. The venous perivascular space may continue along the pial veins travelling through the subarachnoid space to the dura mater [25], where this drainage system is continued by lymphatic vessels along the sinus, and these are ultimately connected to the cervical lymphatic system [3]. Thus, if trigeminal peptidergic afferents innervating the penetrating cerebral arteries are activated, CGRP may be released into the perivascular space and transported via the glymphatic flow into the lymphatic system as a third compartment of CGRP accumulation (Fig. 1a). This issue is all the more interesting in light of recent evidence showing that perivascular spaces are collapsing during experimental cortical spreading depression, which is believed to be the pathophysiological correlate of the migraine aura [44].

Signalling sites for CGRP in the trigeminovascular system CGRP receptors are heteromers, composed of a seven transmembrane spanning protein called calcitonin receptor-like receptor (CLR), a single membrane-spanning protein called receptor activity-modifying protein 1 (RAMP1), and an intracellular component, the receptor component protein
[28]. CGRP binds in a molecular pocket formed by CLR and RAMP1, thus immunohistochemical colocalization of both components can indicate the expression sites of functional CGRP receptors.

In the rodent cranial dura mater, immunofluorescence for both CLR and RAMP1 was found associated with arterial blood vessels, mononuclear cells (mast cells and probably macrophages) and nerve fibres [31]. Highpower confocal images combining CLR and RAMP1 immunoreactivity and markers for axons and glia suggest that Schwann cells but not axons express CGRP receptors, although these findings have been questioned by another group, who found that CGRP receptor immunofluorescence is associated with myelinated A-fibre axons [19].

In the trigeminal ganglion of all species examined so far, apart from blood vessels, neurons of mainly middle sizes and glial cells (Schwann cells and satellite cells) have been found immunopositive for both CGRP receptor components [18, 31]. Likewise, the central processes of these neurons terminating in the outer layers of the spinal trigeminal nucleus and the accompanying glia also express these receptor proteins $[15,31]$. While there is conflicting data regarding whether or not neuronal cell bodies in the spinal trigeminal nucleus express CGRP receptor proteins, there is agreement that trigeminal neurons projecting to the trigeminal brainstem are either expressing CGRP or CGRP receptor components [16, 31].

\section{Signalling of CGRP in the trigeminovascular system}

CGRP is regarded as the most potent vasodilator of intracranial arteries [14]. It has been long known that CGRP binding to its receptor on meningeal (dural and pial) vascular smooth muscle cells induces relaxation through increased intracellular cyclic adenosine monophosphate (cAMP) levels and thereby causing arterial vasodilatation [27] (Fig. 2b). This effect can be observed directly by video imaging, e.g. pial arteries on the medulla [54], and examined indirectly by recording meningeal or medullary blood flow [8]. A weak mast cell degranulating effect of CGRP indicated by histamine release was found in rat dura mater [45] but does probably not translate to human meninges [39]. The question of whether CGRP directly activates meningeal afferents or not has been largely refuted; CGRP does not cause firing nor rapid sensitization of meningeal afferents when it is locally administered onto the rodent dura mater, although application of cAMP analogs can indeed sensitize meningeal afferents [32, 33]. The failure of CGRP to activate meningeal afferents is probably due to the lack of functional CGRP receptors on the nerve fibres innervating the dura mater [31]. Even direct injection of CGRP or CGRP receptor antagonists into the rat trigeminal ganglion did not change the activity or mechanical sensitivity of neurons in the spinal trigeminal 


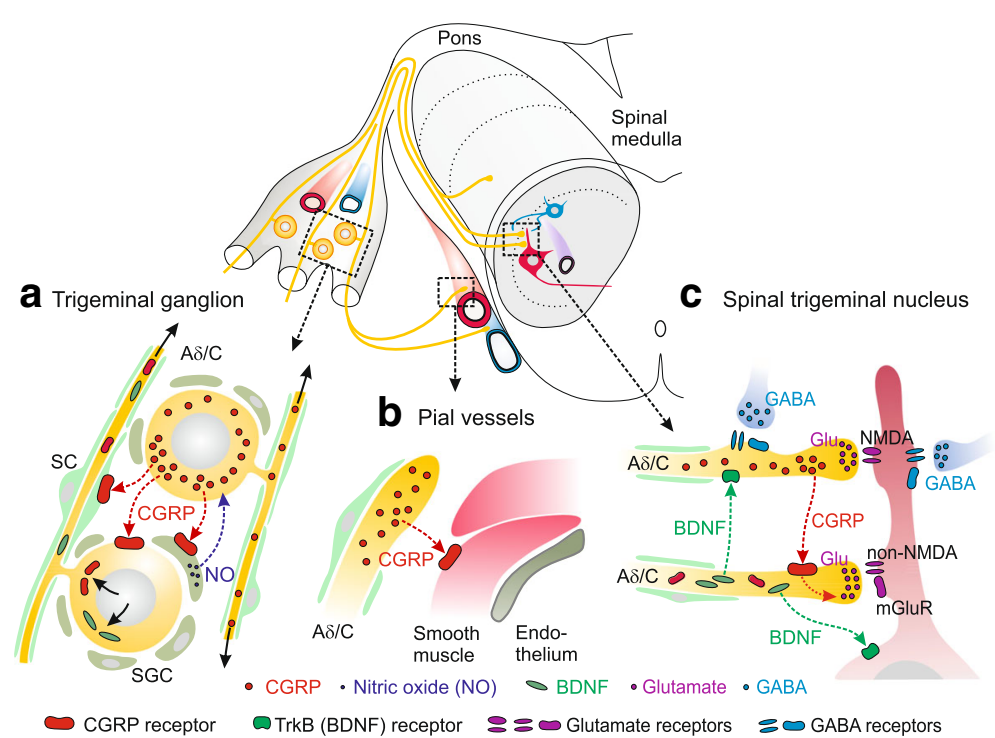

Fig. 2 Scheme of signalling sites for CGRP in the trigeminovascular system. In the trigeminal ganglion (a) CGRP released from neurons may signal to neighbouring neurons, glial satellite cells (GSC) and possibly Schwann cells (SC) expressing CGRP receptors and can thus, via gene expression, influence the production of substances, e.g. nitric oxide (NO), brain-derived neurotrophic factor (BDNF) and CGRP receptor components. These (NO) may signal back to the neurons, or (BDNF, CGRP receptors) may be transported through the central extensions of trigeminal afferents (AS/C) to the spinal trigeminal nucleus. CGRP signalling at arterial vessels, e.g. the pial vessels of the spinal medulla (b), causes vasodilatation and increased blood flow. Within the spinal trigeminal nucleus (c) CGRP is released from central terminals of trigeminal afferents and signals most likely to other central terminals equipped with CGRP receptors, which may lead to increased neurotransmitter (glutamate) release and facilitation of nociceptive transmission. Release of BDNF may pre- and postsynaptically potentiate synaptic transmission. Neurons with inhibitory neurotransmitters (GABA) may counteract the pronociceptive synaptic processes

nucleus with meningeal afferent input [6]. Since systemic administration and iontophoretic application of CGRP receptor antagonists into the spinal trigeminal nucleus are well suited to decrease spinal trigeminal activity [49], we have concluded that CGRP is primarily activating trigeminovascular neurons at their synapses within the trigeminal nucleus [21, 37] (Fig. 2c).

However, these results were all based on short observation periods and did not regard long-term changes caused by activation of cAMP-dependent intracellular signalling mechanisms, which result in the upregulation of transcription factors like extracellular signal-regulated kinase (ERK) and cAMP response element binding protein (CREB) via phosphorylation of protein kinases [42]. Through these mechanisms a variety of receptor proteins like functional purinergic receptors (P2X3) have been shown to be upregulated in trigeminal cell cultures by CGRP application [20,48]. These mechanisms may include signalling between neurons and glia (satellite cells), both of which may express CGRP receptors (Fig. 2a). For example, CGRP released from neurons could cause expression of inducible nitric oxide synthase (iNOS) in satellite cells to produce nitric oxide (NO) [34]. NO could in turn activate the MAP kinase pathway in neighbouring neurons resulting in a higher expression of CGRP, as it was shown in cell cultures [4]. Similar cross-signalling mechanisms involving NO may also occur in vivo leading to an upregulation of CGRP and CGRP receptor proteins, as evidenced by immunohistochemical findings $[7,46]$. Especially interesting are proteins that are transported through the central processes of the ganglion cells to the spinal trigeminal nucleus, where they can be integrated into the presynaptic membrane (Fig. 2a, c). An example of this is brain-derived neurotrophic factor (BDNF), the expression of which is induced by CGRP in cultured trigeminal neurons [5]. BDNF released from central presynaptic terminals may act on preand postsynaptic tyrosine kinase (TrkB) receptors and strengthen nociceptive transmission [22]. Similarly, we assume that CGRP receptors integrated into the presynaptic membrane of central trigeminal terminals are activated by CGRP released from central terminals of other trigeminal afferents and this facilitates neurotransmitter (glutamate) release and thereby nociceptive transmission. Evidence for CGRP-evoked facilitation of central glutamate release comes from experiments on spinal cord slices [50]. The principles outlined above provide an explanation for the mechanism by which inhibition of the CGRP signalling system outside the $\mathrm{BBB}$, i.e., particularly in the trigeminal ganglion, can dampen trigeminal nociception, although the main CGRP dependent pro-nociceptive effects may take place within the spinal trigeminal nucleus. 


\section{Abbreviations}

5-HT: 5-hydroxytryptamine (serotonin); BBB: Blood-brain barrier; BDNF: Brain-derived neurotrophic factor; CAMP: Cyclic adenosine monophosphate; CGRP: Calcitonin gene-related peptide; CLR: Calcitonin receptor-like receptor; CREB: CAMP response element binding protein; CSF: Cerebrospinal fluid; ELISA: Enzyme-linked immuno sorbent assay; ERK: Extracellular signal-regulated kinase; iNOS: Inducible NO synthase; $\mathrm{KCl}$ : Potassium chloride; L-RNA: Ribonucleic acid made with (unnatural) L-ribose; MAP-kinase: Mitogen-activated protein kinase; mRNA: Messenger ribonucleic acid; NO: Nitric oxide; P2X3: Purinergic receptors: RAMP1: Receptor activity-modifying protein 1; TrkB: Tyrosine kinase receptor $\mathrm{B}$, receptor for $\mathrm{BDNF}$

\section{Acknowledgements}

The author would like to thank the President and the Council of the European Headache Federation (EHF) for the opportunity to present and publish the content of this lectureat the EHF Congress 2017 in Rome. The EHF has rendered outstanding services to the community of headache sufferers and therapists, particularly by its educational activities like the European Headache Federation School of Advanced Studies (EHS-SAS). Special thanks go to Dr. Richard Carr for critically reading this manuscript.

\section{Funding}

Not applicable

\section{Availability of data and materials}

Not applicable

\section{Authors' contributions}

All author read and approved the final manuscript.

\section{Ethics approval and consent to participate}

Not applicable

\section{Consent for publication}

Not applicable

\section{Competing interests}

The author declares that he has no competing interests.

\section{Publisher's Note}

Springer Nature remains neutral with regard to jurisdictional claims in published maps and institutional affiliations.

\section{Received: 24 January 2018 Accepted: 23 February 2018}

Published online: 12 March 2018

\section{References}

1. Abbott NJ, Rönnbäck L, Hansson E (2006) Astrocyte-endothelial interactions at the blood-brain barrier. Nat Rev Neurosci 7:41-53. https://doi.org/10.1038/nrn1824.

2. Amara SG, Jonas V, Rosenfeld MG et al (1982) Alternative RNA processing in calcitonin gene expression generates mRNAs encoding different polypeptide products. Nature 298:240-244.

3. Aspelund A, Antila S, Proulx ST et al (2015) A dural lymphatic vascular system that drains brain interstitial fluid and macromolecules. J Exp Med 212:991-999. https://doi.org/10.1084/jem.20142290

4. Bellamy J, Bowen EJ, Russo AF, Durham PL (2006) Nitric oxide regulation of calcitonin gene-related peptide gene expression in rat trigeminal ganglia neurons. Eur J Neurosci 23:2057-2066. https://doi.org/10.1111/j.1460-9568.2006.04742.x.

5. Buldyrev I, Tanner NM, Hsieh H et al (2006) Calcitonin gene-related peptide enhances release of native brain-derived neurotrophic factor from trigeminal ganglion neurons. J Neurochem 99:1338-1350. https://doi.org/10.1111/j.1471-4159.2006.04161.x.

6. Covasala O, Stirn SL, Albrecht S et al (2012) Calcitonin gene-related peptide receptors in rat trigeminal ganglion do not control spinal trigeminal activity. J Neurophysiol 108:431-440. https://doi.org/10.1152/jn.00167.2011.

7. Dieterle A, Fischer MJM, Link AS et al (2011) Increase in CGRP- and nNOS-immunoreactive neurons in the rat trigeminal ganglion after infusion of an NO donor. Cephalalgia Int J. Headache 31:31-42. https://doi.org/10.1177/0333102410375725

8. Dux M, Will C, Eberhardt M et al (2017) Stimulation of rat cranial dura mater with potassium chloride causes CGRP release into the cerebrospinal fluid and increases medullary blood flow. Neuropeptides 64:61-68. https://doi.org/10.1016/j.npep.2017.02.080.

9. Eberhardt M, Hoffmann T, Sauer SK et al (2008) Calcitonin gene-related peptide release from intact isolated dorsal root and trigeminal ganglia. Neuropeptides 42:311-317. https://doi.org/10.1016/j.npep.2008.01.002.

10. Ebersberger A, Averbeck B, Messlinger K, Reeh PW (1999) Release of substance $P$, calcitonin gene-related peptide and prostaglandin E2 from rat dura mater encephali following electrical and chemical stimulation in vitro. Neuroscience 89:901-907.

11. Edvinsson L, Ekman R, Jansen I et al (1987) Calcitonin gene-related peptide and cerebral blood vessels: distribution and vasomotor effects. J Cereb Blood Flow Metab Off J Int Soc Cereb Blood Flow Metab 7:720-728. https://doi.org/10.1038/jcbfm.1987.126.

12. Edvinsson L, Fredholm BB, Hamel E et al (1985) Perivascular peptides relax cerebral arteries concomitant with stimulation of cyclic adenosine monophosphate accumulation or release of an endothelium-derived relaxing factor in the cat. Neurosci Lett 58:213-217.

13. Edvinsson L, Goadsby PJ (1995) Neuropeptides in the cerebral circulation: relevance to headache. Cephalalgia Int J Headache 15:272-276. https://doi.org/10.1046/j.1468-2982.1995.1504272.x.

14. Edvinsson L, Jansen I, Cunha e Sa M, Gulbenkian S (1994) Demonstration of neuropeptide containing nerves and vasomotor responses to perivascular peptides in human cerebral arteries. Cephalalgia Int J Headache 14:88-96

15. Eftekhari S, Edvinsson L (2011) Calcitonin gene-related peptide (CGRP) and its receptor components in human and rat spinal trigeminal nucleus and spinal cord at C1-level. BMC Neurosci 12:112. https://doi. org/10.1186/1471-2202-12-112.

16. Eftekhari S, Gaspar RC, Roberts R et al (2016) Localization of CGRP receptor components and receptor binding sites in rhesus monkey brainstem: a detailed study using in situ hybridization, immunofluorescence, and autoradiography. J Comp Neurol 524:90-118. https://doi.org/10.1002/cne.23828.

17. Eftekhari S, Salvatore CA, Calamari A et al (2010) Differential distribution of calcitonin gene-related peptide and its receptor components in the human trigeminal ganglion. Neuroscience 169:683-696. https://doi.org/10.1016/j. neuroscience.2010.05.016

18. Eftekhari S, Salvatore CA, Johansson S et al (2015) Localization of CGRP, CGRP receptor, PACAP and glutamate in trigeminal ganglion. Relation to the bloodbrain barrier. Brain Res 1600:93-109. https://doi.org/10.1016/j.brainres.2014.11.031.

19. Eftekhari S, Warfvinge K, Blixt FW, Edvinsson L (2013) Differentiation of nerve fibers storing CGRP and CGRP receptors in the peripheral trigeminovascular system. J Pain Off J Am Pain Soc 14:1289-1303. https://doi.org/10.1016/j. jpain.2013.03.010

20. Fabbretti E, D'Arco M, Fabbro A et al (2006) Delayed upregulation of ATP P2X3 receptors of trigeminal sensory neurons by calcitonin gene-related peptide. J Neurosci 26:6163-6171. https://doi.org/10. 1523/JNEUROSCI.0647-06.2006.

21. Fischer MJM, Koulchitsky S, Messlinger K (2005) The nonpeptide calcitonin gene-related peptide receptor antagonist BIBN4096BS lowers the activity of neurons with meningeal input in the rat spinal trigeminal nucleus. J Neurosci 25:5877-5883. https://doi.org/10.1523/JNEUROSCI.0869-05.2005.

22. Garraway SM, Huie JR (2016) Spinal plasticity and behavior: BDNF-induced Neuromodulation in uninjured and injured spinal cord. Neural Plast 2016: 9857201. doi: https://doi.org/10.1155/2016/9857201.

23. Gupta S, Amrutkar DV, Mataji A et al (2010) Evidence for CGRP re-uptake in rat dura mater encephali. Br J Pharmacol 161:1885-1898. https://doi.org/10. 1111/j.1476-5381.2010.01012.x.

24. Hoffmann J, Wecker $S$, Neeb L et al (2012) Primary trigeminal afferents are the main source for stimulus-induced CGRP release into jugular vein blood and CSF. Cephalalgia Int J Headache 32:659-667. https://doi.org/10.1177/ 0333102412447701

25. Iliff JJ, Goldman SA, Nedergaard M (2015) Implications of the discovery of brain lymphatic pathways. Lancet Neurol 14:977-979. https://doi.org/10. 1016/S1474-4422(15)00221-5

26. Iliff JJ, Lee H, Yu M et al (2013) Brain-wide pathway for waste clearance captured by contrast-enhanced MRI. J Clin Invest 123:1299-1309. https://doi. org/10.1172/JCl67677 
27. Jansen-Olesen I, Mortensen A, Edvinsson L (1996) Calcitonin gene-related peptide is released from capsaicin-sensitive nerve fibres and induces vasodilatation of human cerebral arteries concomitant with activation of adenylyl cyclase. Cephalalgia Int J Headache 16:310-316.

28. Juaneda C, Dumont Y, Quirion R (2000) The molecular pharmacology of CGRP and related peptide receptor subtypes. Trends Pharmacol Sci 21:432-438

29. Kageneck C, Nixdorf-Bergweiler BE, Messlinger K, Fischer MJ (2014) Release of CGRP from mouse brainstem slices indicates central inhibitory effect of triptans and kynurenate. J Headache Pain 15:7. https://doi.org/10.1186/1129-2377-15-7.

30. Lee Y, Kawai Y, Shiosaka S et al (1985) Coexistence of calcitonin gene-related peptide and substance $P$-like peptide in single cells of the trigeminal ganglion of the rat: immunohistochemical analysis. Brain Res 330:194-196.

31. Lennerz JK, Rühle V, Ceppa EP et al (2008) Calcitonin receptor-like receptor (CLR), receptor activity-modifying protein 1 (RAMP1), and calcitonin generelated peptide (CGRP) immunoreactivity in the rat trigeminovascular system: differences between peripheral and central CGRP receptor distribution. J Comp Neurol 507:1277-1299. https://doi.org/10.1002/cne.21607.

32. Levy D, Burstein R, Strassman AM (2005) Calcitonin gene-related peptide does not excite or sensitize meningeal nociceptors: implications for the pathophysiology of migraine. Ann Neurol 58:698-705. https://doi.org/10. 1002/ana.20619.

33. Levy D, Strassman AM (2002) Distinct sensitizing effects of the CAMP-PKA second messenger cascade on rat dural mechanonociceptors. J Physiol 538:483-493.

34. Li J, Vause CV, Durham PL (2008) Calcitonin gene-related peptide stimulation of nitric oxide synthesis and release from trigeminal ganglion glial cells. Brain Res 1196:22-32. https://doi.org/10.1016/j.brainres.2007.12.028.

35. Mason RT, Peterfreund RA, Sawchenko PE et al (1984) Release of the predicted calcitonin gene-related peptide from cultured rat trigeminal ganglion cells. Nature 308:653-655.

36. McCulloch J, Uddman R, Kingman TA, Edvinsson L (1986) Calcitonin generelated peptide: functional role in cerebrovascular regulation. Proc Natl Acad Sci U S A 83:5731-5735.

37. Messlinger K, Fischer MJM, Lennerz JK (2011) Neuropeptide effects in the trigeminal system: pathophysiology and clinical relevance in migraine. Keio J Med 60:82-89.

38. Messlinger K, Hanesch $U$, Baumgärtel $M$ et al (1993) Innervation of the dura mater encephali of cat and rat: ultrastructure and calcitonin generelated peptide-like and substance P-like immunoreactivity. Anat Embryol (Berl) 188:219-237.

39. Ottosson A, Edvinsson $L$ (1997) Release of histamine from dural mast cells by substance $P$ and calcitonin gene-related peptide. Cephalalgia Int J Headache 17:166-174. https://doi.org/10.1046/j.1468-2982.1997.1703166.x.

40. Ray BS, Wolff HG (1940) Experimental studies on headache: pain sensitive structures of the head and their significance in headache. Arch Surg 1:813856.

41. Rosenfeld MG, Mermod JJ, Amara SG et al (1983) Production of a novel neuropeptide encoded by the calcitonin gene via tissue-specific RNA processing. Nature 304:129-135.

42. Russell FA, King R, Smillie S-J et al (2014) Calcitonin gene-related peptide: physiology and pathophysiology. Physiol Rev 94:1099-1142. https://doi.org/ 10.1152/physrev.00034.2013.

43. Schaible HG, Ebersberger A, Peppel P et al (1997) Release of immunoreactive substance $P$ in the trigeminal brain stem nuclear complex evoked by chemical stimulation of the nasal mucosa and the dura mater encephali-a study with antibody microprobes. Neuroscience 76:273-284.

44. Schain AJ, Melo-Carrillo A, Strassman AM, Burstein R (2017) Cortical spreading depression closes Paravascular space and impairs Glymphatic flow: implications for migraine headache. J Neurosci 37:2904-2915. https:// doi.org/10.1523/JNEUROSCI.3390-16.2017.

45. Schwenger N, Dux M, de Col R et al (2007) Interaction of calcitonin generelated peptide, nitric oxide and histamine release in neurogenic blood flow and afferent activation in the rat cranial dura mater. Cephalalgia Int J Headache 27:481-491. https://doi.org/10.1111/j.1468-2982.2007.01321.x.

46. Seiler K, Nusser Jl, Lennerz JK et al (2013) Changes in calcitonin gene-related peptide (CGRP) receptor component and nitric oxide receptor (sGC) immunoreactivity in rat trigeminal ganglion following glyceroltrinitrate pretreatment. J Headache Pain 14:74. https://doi.org/10.1186/1129-2377-14-74.

47. Sekiguchi T, Kuwasako K, Ogasawara M et al (2016) Evidence for conservation of the Calcitonin Superfamily and activity-regulating mechanisms in the basal chordate Branchiostoma floridae: insights into the molecular and functional evolution in chordates. J Biol Chem 291:23452356. https://doi.org/10.1074/jbc.M115.664003.

48. Simonetti M, Giniatullin R, Fabbretti E (2008) Mechanisms mediating the enhanced gene transcription of $\mathrm{P} 2 \mathrm{X} 3$ receptor by calcitonin gene-related peptide in trigeminal sensory neurons. J Biol Chem 283:18743-18752. https://doi.org/10.1074/jbc.M800296200.

49. Storer RJ, Akerman S, Goadsby PJ (2004) Calcitonin gene-related peptide (CGRP) modulates nociceptive trigeminovascular transmission in the cat. $\mathrm{Br}$ J Pharmacol 142:1171-1181. https://doi.org/10.1038/sj.bjp.0705807.

50. Takhshid MA, Owji AA, Panjehshahin MR (2007) In vitro effects of adrenomedullin and calcitonin gene related peptide on the release of serotonin and amino acids from rat dorsal spinal cord. Neurosci Lett 420: 193-197. https://doi.org/10.1016/j.neulet.2007.03.061.

51. Tarasoff-Conway JM, Carare RO, Osorio RS et al (2015) Clearance systems in the brain-implications for Alzheimer disease. Nat Rev Neurol 11:457-470. https://doi.org/10.1038/nrneurol.2015.119.

52. Uddman R, Edvinsson L, Ekman R et al (1985) Innervation of the feline cerebral vasculature by nerve fibers containing calcitonin gene-related peptide: trigeminal origin and co-existence with substance P. Neurosci Lett 62:131-136.

53. Wiesenfeld-Hallin Z, Hökfelt T, Lundberg JM et al (1984) Immunoreactive calcitonin gene-related peptide and substance $P$ coexist in sensory neurons to the spinal cord and interact in spinal behavioral responses of the rat. Neurosci Lett 52:199-204.

54. Will C, Messlinger K, Fischer MJM (2016) Vessel diameter measurements at the medullary brainstem in vivo as an index of trigeminal activity. Brain Res 1632:51-57. https://doi.org/10.1016/j.brainres.2015.12.013.

55. Zhang ET, Inman CB, Weller RO (1990) Interrelationships of the pia mater and the perivascular (Virchow-Robin) spaces in the human cerebrum. J Anat 170:111-123.

\section{Submit your manuscript to a SpringerOpen ${ }^{\circ}$ journal and benefit from:}

- Convenient online submission

- Rigorous peer review

- Open access: articles freely available online

- High visibility within the field

- Retaining the copyright to your article

Submit your next manuscript at $>$ springeropen.com 